\title{
Expression of DNMTs and MBD2 in GIST
}

\author{
MIAO HE ${ }^{1}$, JING FAN $^{2}$, RONG JIANG $^{3}$, WEI-XUE TANG $^{4}$ and ZI-WEI WANG ${ }^{1}$ \\ Departments of ${ }^{1}$ General Surgery and ${ }^{2}$ Emergency, The First Affiliated Hospital of Chongqing Medical University; \\ ${ }^{3}$ Laboratory of Stem Cell and Tissue Engineering, Institute of Basic Medicine of Chongqing Medical University; \\ ${ }^{4}$ Laboratory Research Center, The First Affiliated Hospital of Chongqing Medical University, Chongqing 400016, P.R. China
}

Received September 8, 2012; Accepted October 16, 2012

DOI: $10.3892 /$ br.2012.34

\begin{abstract}
The aim of this study was to investigate the protein expression of DNA methyltransferases (DNMTs, including DNMT1, DNMT2, DNMT3A, DNMT3B and DNMT3L) and methyl-CpG-binding domain protein 2 (MBD2) in gastrointestinal stromal tumor (GIST). Immunohistochemistry and western blot analysis were used to detect expression of DNMT and MBD2 in 15 pairs of adult GIST and matched non-tumor tissues. The protein expression of DNMT1, DNMT2, DNMT3B, DNMT3L and MBD2 was significantly higher in adult GISTs compared to the matched non-tumor tissues $(\mathrm{P}<0.05)$. However, no significant difference was detected in the protein expression of DNMT3A between tumor and non-tumor tissues $(\mathrm{P}>0.05)$. Associations between DNMT1 expression and mitotic index, DNMT3B expression and tumor size, as well as DNMT3L expression and Helicobacter pylori infection were detected in GISTs $(\mathrm{P}<0.05)$. In conclusion, GISTs exhibit a high protein expression of DNMT (with the exception of DNMT3A) and MBD2.
\end{abstract}

\section{Introduction}

Epigenetics is the study of inherited genetic changes that occur without changes to the naked DNA sequence, including DNA methylation, histone modification, chromatin remodeling and non-coding RNAs (1). DNA methylation is the most widely researched epigenetic alteration in human tumors. Human tumor cells exhibit abnormal DNA methylation patterns including the hypermethylation of $\mathrm{CpG}$ islands in tumor-suppressor genes (TSGs) and a global loss of DNA methylation in the genome (2). These changes, correlated with the inactivation of TSGs and the activation of oncogenes, may promote tumor progression (3). Abnormal expression of

Correspondence to: Professor Zi-Wei Wang, Department of General Surgery, The First Affiliated Hospital of Chongqing Medical University, 1st Youyi Road, Yuanjiagang, Yuzhong, Chongqing 400016, P.R. China

E-mail: wangziwei571@163.com

Key words: DNA methyltransferase, methyl-CpG-binding domain protein 2, gastrointestinal stromal tumor
DNA methyltransferase (DNMT) and demethylase (MBD2) are regarded as important causes for the aberrant DNA methylation that occurs in tumors (4). High levels of DNMT and MBD2 expression may contribute to tumor progression through the hypermethylation-mediated inactivation of TSGs in $\mathrm{CpG}$ islands (5). In this study, the gastrointestinal stromal tumor (GIST) was used to analyze the expression of DNMT (DNMT1, DNMT2, DNMT3A, DNMT3B and DNMT3L) and MBD2. This study is considered to be useful for future epigenetic investigations on GIST.

\section{Materials and methods}

Ethics statement. The experimental procedures were approved by the Ethics Committee of The First Affiliated Hospital of the Chongqing Medical University (Chongqing, China).

Clinical specimens. Fifteen pairs of adult GIST and matched non-tumor tissues (located $>2 \mathrm{~cm}$ from the tumor area) were obtained from the gastric resection specimens in The First Affiliated Hospital of the Chongqing Medical University. The GIST samples were confirmed by pathological analysis (including KIT: +, CD34: +, DOG-1: +, SMA: +, S-100: -). The samples were prepared for immunohistochemistry and western blot analysis to determine the expression of DNMT and MBD2.

Immunohistochemistry. The streptavidin-peroxidase (SP) method was performed. Primary antibodies specific to DNMT1, DNMT2, DNMT3A, DNMT3B, DNMT3L and MBD2 were purchased from Santa Cruz Biotechnology, Inc., Santa Cruz, CA, USA. The SP and DAB kits were obtained from the Beijing Zhongshan Company (Beijing, China).

Evaluation of staining (immunohistochemistry). Expression of DNMT and MBD2 were assessed by scoring the staining intensity and proportion. The staining intensity was determined as negative, 0 ; light, 1 ; moderate, 2 or strong, 3 . The staining proportion was determined as $1(\leq 25 \%), 2(\leq 50 \%)$, $3(\leq 75 \%)$ or $4(>75 \%)$. The two values were multiplied for each slide to produce a terminal score. In case the score was higher in the tumor compared to the matched control, the pair of tissues was marked ' + '. The opposite condition was marked '-'. In case the scores were the same, the pair was marked ' 0 '. 
A

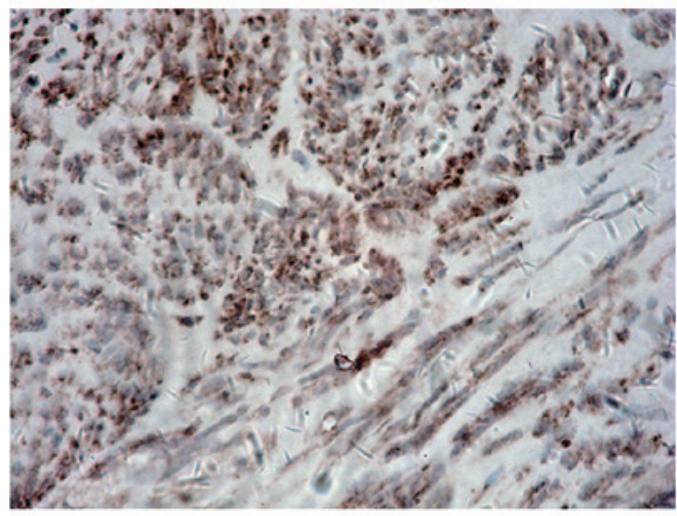

C

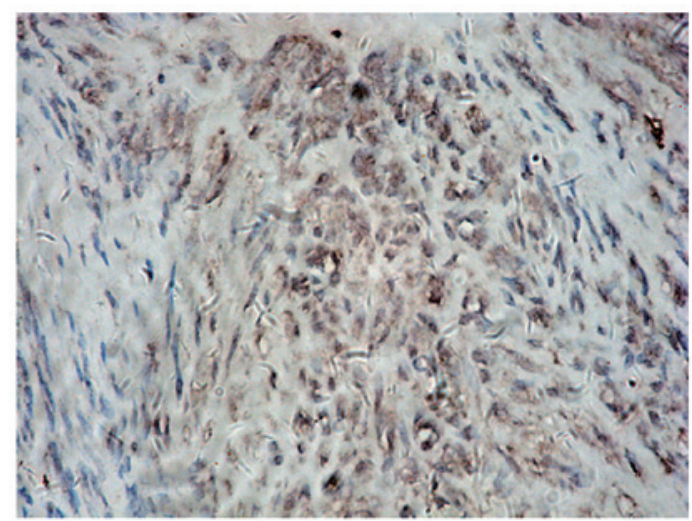

E

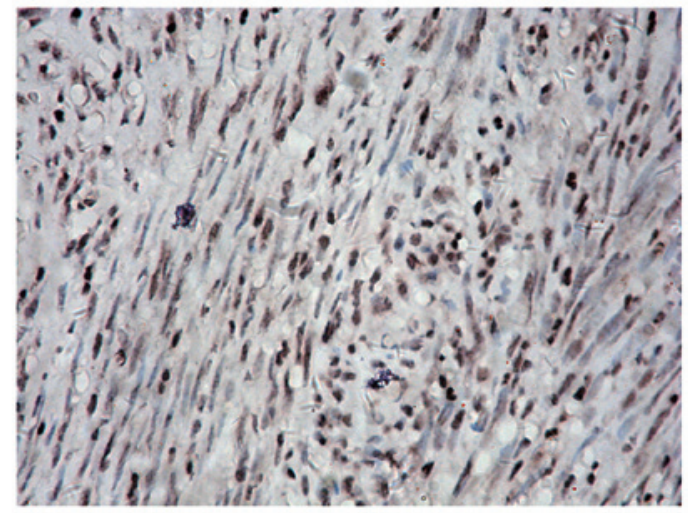

B

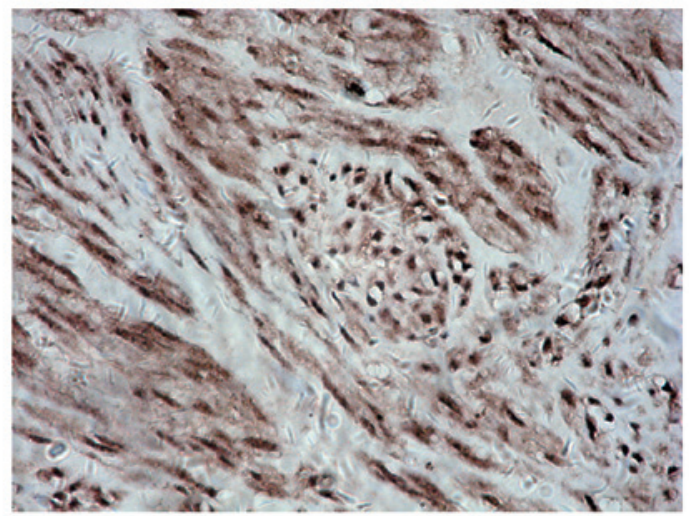

D

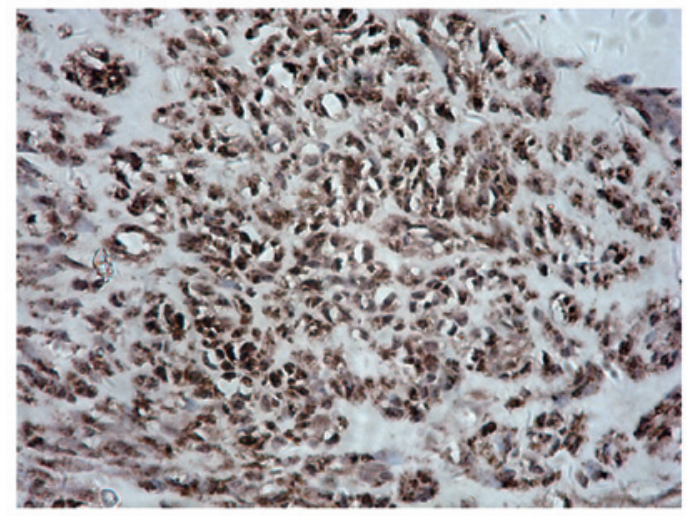

$\mathbf{F}$

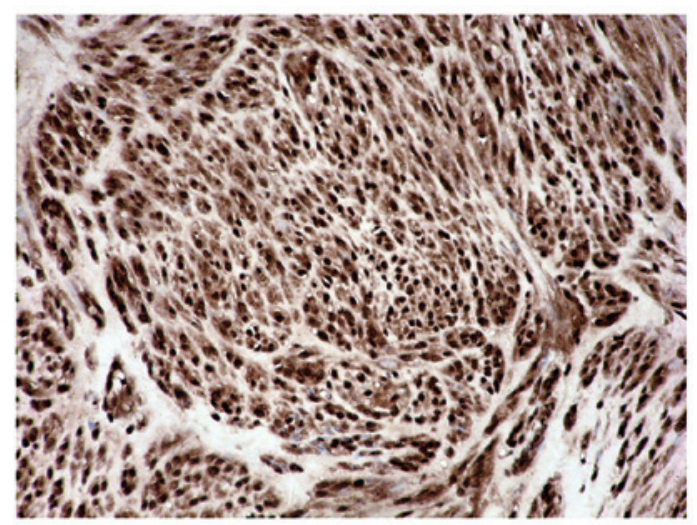

Figure 1. Expression of DNA methyltransferases (DNMTs) and methyl-CpG-binding domain protein 2 (MBD2) in gastrointestinal stromal tumor (GIST), Expression of (A) DNMT1, (B) DNMT2, (C) DNMT3A, (D) DNMT3B, (E) DNMT3L and (F) MBD2 in GIST.

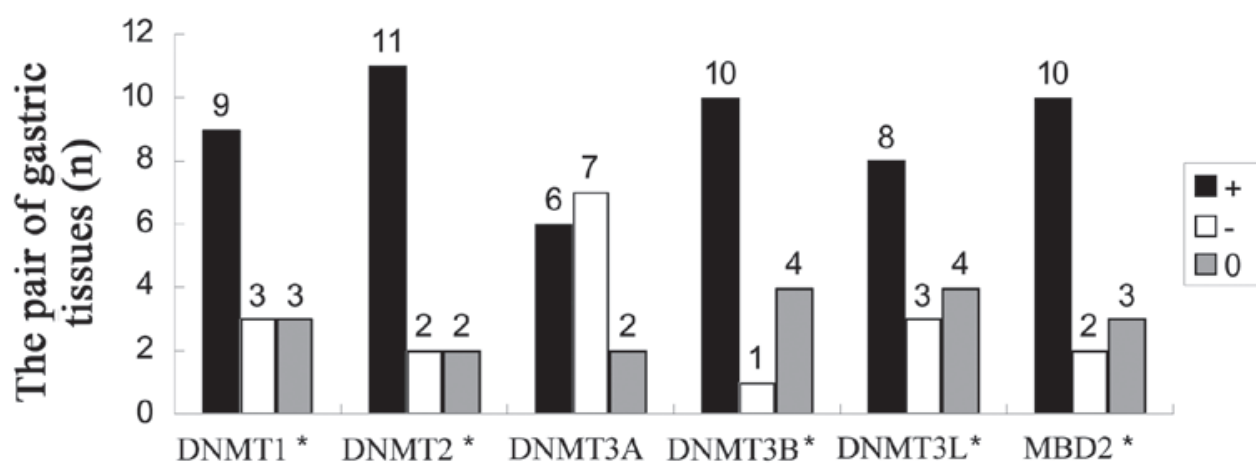

Figure 2. Comparison of DNA methyltransferases (DNMTs) and methyl-CpG-binding domain protein 2 (MBD2) expression in gastrointestinal stromal tumors (GISTs) and matched non-tumor tissues by immunohistochemistry is shown. ' + ', protein expression was higher in tumor compared to matched non-tumor tissue; '-', protein expression was lower in tumor compared to matched non-tumor tissue; '0', protein expression was similar in tumor and matched non-tumor tissue. Expression of DNMT1, DNMT2, DNMT3B, DNMT3L and MBD2 was significantly higher in GIST tissues compared to matched non-tumor tissues $($ ( $\mathrm{P}<0.05$, Wilcoxon signed-rank test). For DNMT3A, the expression difference was not significant ( $\mathrm{P}>0.05$, Wilcoxon signed-rank test). 
Table I. Positive DNMT and MBD2 expression in differential clinical characteristics of GIST.

Expression (\%)

Clinical

characteristics

No.

DNMT1 DNMT2

DNMT3A

DNMT3B

DNMT3L

MBD2

\section{Gender}

Male

$6 \quad 1(16.7)$

4 (66.7)

2 (33.3)

5 (83.3)

5 (83.3)

$6(100)$

Female

$9 \quad 4(44.4)$

9 (100)

5 (55.6)

0.58

0.14

0.61

8 (88.9)

7 (77.8)

8 (88.9)

P-value

Age (years)

$>50$
$\leq 50$

$\begin{array}{rc}11 & 4(36.4) \\ 4 & 1(25) \\ & 1\end{array}$

$9(81.8)$
$4(100)$
1

$6(54.5)$

1 (25)
3 (75)
0.48

$10(90.9)$

0.57
9 (81.8)
$3(75)$

P-value

$\begin{array}{rc}12 & 5(41.7) \\ 3 & 0(0) \\ & 0.51\end{array}$

$10(83.3)$
$3(100)$
1

$5(41.7)$
$2(66.7)$
0.57

$\begin{array}{cc}10(90.9) & 4(36.4) \\ 3(75) & 3(75) \\ 0.48 & 0.28\end{array}$

$1(9.1)$
$4(100)$
0.01

0.48

0.28
12 (100)
1 (33.3)
0.03

\begin{tabular}{|c|c|c|c|c|c|c|c|}
\hline Positive & 13 & $5(38.5)$ & $11(84.6)$ & $7(53.8)$ & $13(100)$ & $12(92.3)$ & $13(100)$ \\
\hline Negative & 2 & $0(0.0)$ & $2(100)$ & $0(0)$ & $0(0)$ & $0(0)$ & $1(50)$ \\
\hline P-value & & 0.52 & 1 & 0.47 & 0.01 & 0.03 & 0.13 \\
\hline
\end{tabular}
9 (81.8)
4 (100)
1
$11(91.7)$
1 (33.3)
0.08
$2(66.7)$
(66.7)
0.2

H. pylori infection

$\chi^{2}$ test and Fisher's exact test. DNMT, DNA methyltransferase; MBD2, methyl-CpG-binding domain protein 2; GIST, gastrointestinal stromal tumor; HPF, high-power fields; H. pylori, Helicobacter pylori.

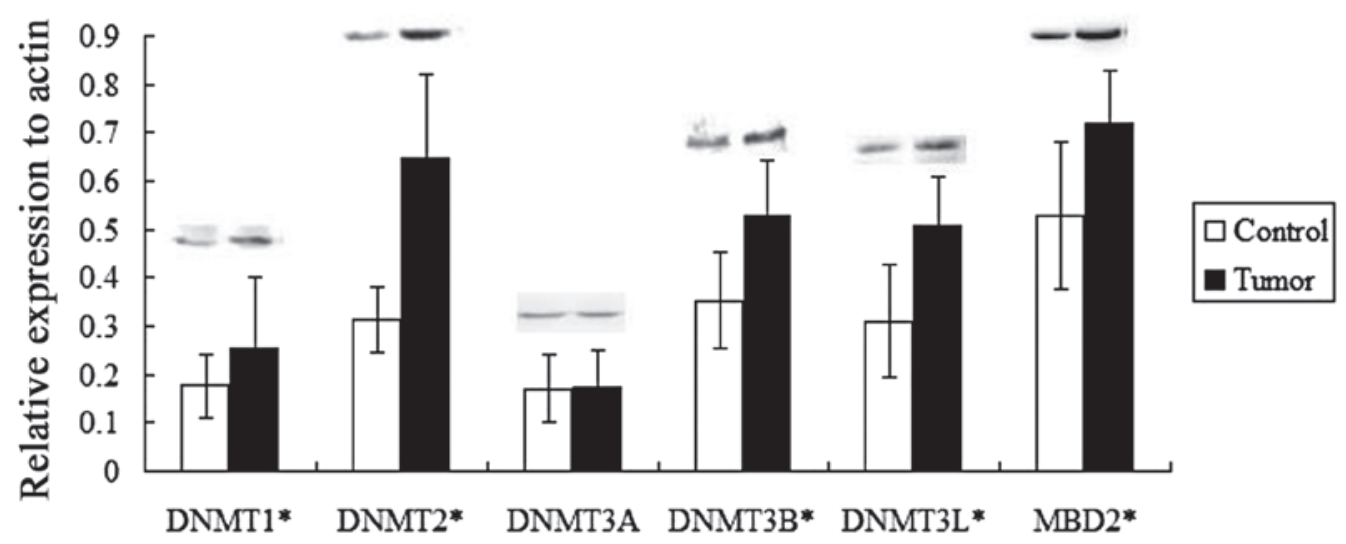

Figure 3. Differential expression of DNA methyltransferases (DNMTs) and methyl-CpG-binding domain protein 2 (MBD2) in gastrointestinal stromal tumor (GIST) tissues and matched non-tumor tissues by western blot analysis. $0.176 \pm 0.065,0.312 \pm 0.068,0.171 \pm 0.068,0.352 \pm 0.099,0.31 \pm 0.115$ and $0.529 \pm 0.151$ were corresponding to the relative expression of DNMT1, 2, 3A, 3B, 3L and MBD2, respectively, to actin in non-tumor tissues. $0.253 \pm 0.147,0.645 \pm 0.174$, $0.175 \pm 0.075,0.529 \pm 0.112,0.506 \pm 0.103$ and $0.719 \pm 0.109$ were corresponding to the relative expression of DNMT1, 2, 3A, 3B, 3L and MBD2, respectively, to Actin in GIST. With the exception of DNMT3A, expression of DNMT and MBD2 was significantly higher in GIST tissues compared to matched non-tumor tissues $\left({ }^{*} \mathrm{P}<0.05\right.$, t-test, mean $\left.\pm \mathrm{SD}, \mathrm{n}=15\right)$. Actin was used as the internal control.

Terminal scores of 0-2 were defined as negative expression, while 3-12 were defined as positive expression.

Western blot analysis. The western blot analysis was carried out as decribed in a previous study (6). Materials used in the analysis were obtained from the Beyotime Company (Jiangsu, China).

Statistical analysis. Data were presented as mean \pm SD. Standard statistical analysis was performed using the SPSS 
17.0 package software. The Wilcoxon signed-rank, $\chi^{2}$, Fisher's exact and Student's t-tests were used in this study. $\mathrm{P}<0.05$ was considered to indicate a statistically significant difference.

\section{Results}

Expression of DNMT and MBD2 in GIST tissues. GIST was detected to express DNMT and MBD2 proteins (Fig. 1). With the exception of DNMT3A, expression of DNMT and MBD2 were significantly higher in GIST tissues compared to matched non-tumor tissues (Figs. 2 and 3).

Association between expression of DNMTs and MBD2 and clinical parameters of GIST. There was no statistically significant association between expression of DNMTs, MBD2 and gender or age in GISTs as detected by the $\chi^{2}$ and the Fisher's exact tests $(\mathrm{P}>0.05)$. However, significant associations were observed between DNMT1 expression and the mitotic index; and DNMT3B expression and tumor size, Helicobacter pylori infection; DNMT3L expression and Helicobacter pylori infection in GISTs $(\mathrm{P}<0.05)$ (Table I).

\section{Discussion}

GIST is the most common mesenchymal tumor in the gastrointestinal tract that usually arises in the stomach (60\%) (7). Seventy percent of GISTs present with non-specific clinical symptoms and the risk assessments for GIST are determined by tumor size, anatomic site and mitotic activity (8). Early events in GIST development are activating mutations in KIT or PDGFRA, which occur in most GISTs and encode for mutated tyrosine receptor kinases that are the causes for uncontrolled kinase activity and result in alterations to the cell cycle and apoptosis $(9,10)$. Immunoreactive detection of KIT (CD117), DOG1, CD34, SMA, CALDES, DES, and S-100 is a useful method for the differential diagnosis of GIST from other mesenchymal tumors $(11,12)$. Tyrosine kinase inhibitor imatinib mesylate and surgery are known to be traditional treatments for GISTs. However, certain GISTs $(\sim 10-15 \%$ in adults, $85-90 \%$ in children) are characterized by the lack of KIT or PDGFRA mutations $(13,14)$, suggesting a complex pathogenesis of GIST.

DNMT and MBD2 are important functional proteins in epigenetics. DNMT1 methylates hemimethylated $\mathrm{CpG}$ palindromes in DNA and is referred to as a 'maintenance' DNA methylation enzyme that faithfully copies the DNA methylation pattern from the parent to the daughter strand of DNA after replication. DNMT2 contains the catalytic signature motifs of conventional (cytosine-5) DNMTs. It has comparably low DNMT activity, but has shown transfer RNA (tRNA) methyltransferase activity (15). DNMT3A and DNMT3B have been termed de novo methyltransferases and are thought to be involved in the establishment of methylation patterns. DNMT3L lacks the methyltransferase catalytic domain but is involved in the establishment of DNA methylation by recruiting or activating other de novo DNMTs (16-18). MBD2 is capable of binding specifically to methylated DNA and can repress transcription from methylated gene promoters (19). Notably, MBD2 has also been reported to function as a demethylase to activate transcription (20), as DNA methylation causes gene silencing.

Epigenetic alterations, such as promoter hypermethylation leading to chromatin remodeling and the silencing of cancer-related genes are highly involved in tumor development (21). A common assumption is that the abnormal expression of DNMTs and MBD2 may contribute to tumor progression through hypermethylation-mediated TSG inactivation in $\mathrm{CpG}$ islands. A number of studies have proven that tumors exhibit a high expression of DNMT and MBD2 $(19,22)$. However, their involvement in GIST has yet to be elucidated.

In this study, we found almost all the DNMTs, with the exception of DNMT3A, while MBD2 proteins were significantly higher in GIST tissues compared to matched control tissues. This result is consistent with previous studies on the DNMT expression in tumors, suggesting that, besides KIT and the PDGFRA mutation, epigenetic alterations may also be potentially involved in the pathogenesis of GIST. Nevertheless, the associations between DNMT and clinical parameters in GIST indicate the underlying diagnostic value of DNMT expression for GIST. Thus, more GIST samples are required to verify the above-mentioned results. Additionally, to confirm the DNA methylation status of tumor-related genes in GISTs and the potential suppressive effect of the DNMT inhibitor, such as 5-aza-2'-deoxycytidine on GIST further investigations are required in the future.

In conclusion, GIST may exhibit high expression of DNMT and MBD2 protein, thus demonstrating potential associations between DNMT expression and clinical parameters in GIST.

\section{References}

1. Esteller M: Cancer epigenetics for the 21st century: what's next? Genes Cancer 2: 604-606, 2011.

2. Daniel FI, Cherubini K, Yurgel LS, de Figueiredo MA and Salum FG: The role of epigenetic transcription repression and DNA methyltransferases in cancer. Cancer 117: 677-687, 2011.

3. Bender CM, Pao MM and Jones PA: Inhibition of DNA methylation by 5-aza-2'-deoxycytidine suppresses the growth of human tumor cell lines. Cancer Res 58: 95-101, 1998.

4. Fang JY, Cheng ZH, Chen YX, Lu R, Yang L, Zhu HY and Lu LG: Expression of Dnmt1, demethylase, MeCP2 and methylation of tumor-related genes in human gastric cancer. World $\mathrm{J}$ Gastroenterol 10: 3394-3398, 2004.

5. Vertino PM, Yen RW, Gao J and Baylin SB: De novo methylation of $\mathrm{CpG}$ island sequences in human fibroblasts overexpression DNA (cytosine-5-)-methyltransferase. Mol Cell Biol 16: 4555-4565, 1996.

6. Jung Y, Park J, Kim TY, Park JH, Jong HS, Im SA, Robertson KD, Bang YJ and Kim TY: Potential advantages of DNA methyltransferase 1 (DNMT1)-targeted inhibition for cancer therapy. J Mol Med (Berl) 85: 1137-1148, 2007.

7. Foo WC, Liegl-Atzwanger B and Lazar AJ: Pathology of gastrointestinal stromal tumors. Clin Med Insights Pathol 5: 23-33, 2012.

8. Fletcher CD, Berman JJ, Corless C, Gorstein F, Lasota J, Longley BJ, Miettinen M, O'Leary TJ, Remotti H, Rubin BP, Shmookler B, Sobin LH and Weiss SW: Diagnosis of gastrointestinal stromal tumors: a consensus approach. Int J Surg Pathol 10: 81-89, 2002.

9. Hirota S, Isozaki K, Moriyama Y, Hashimoto K, Nishida T, Ishiguro S, Kawano K, Hanada M, Kurata A, Takeda M, Muhammad Tunio G, Matsuzawa Y, Kanakura Y, Shinomura Y and Kitamura Y: Gain-of-function mutations of c-kit in human gastrointestinal stromal tumors. Science 279: 577-580, 1998. 
10. Heinrich MC, Corless CL, Demetri GD, Blanke CD, von Mehren M, Joensuu H, McGreevey LS, Chen CJ, Van den Abbeele AD, Druker BJ, Kiese B, Eisenberg B, Roberts PJ, Singer S, Fletcher CD, Silberman S, Dimitrijevic S and Fletcher JA: Kinase mutations and imatinib response in patients with metastatic gastrointestinal stromal tumor. J Clin Oncol 21: 4342-4349, 2003.

11. Miettinen M, Sobin LH and Lasota J: Gastrointestinal stromal tumors of the stomach: a clinicopathologic, immunohistochemical, and molecular genetic study of 1765 cases with long-term follow-up. Am J Surg Pathol 29: 52-68, 2005.

12. Novelli M, Rossi S, Rodriguez-Justo M, Taniere P, Seddon B, Toffolatti L, Sartor C, Hogendoorn PC, Sciot R, Van Glabbeke M, Verweij J, Blay JY, Hohenberger P, Flanagan A and Dei Tos AP: DOG1 and CD117 are the antibodies of choice in the diagnosis of gastrointestinal stromal tumours. Histopathology 57: 259-270, 2010.

13. Janeway KA, Liegl B, Harlow A, Le C, Perez-Atayde A, Kozakewich H, Corless CL, Heinrich MC and Fletcher JA: Pediatric KIT wild-type and platelet-derived growth factor receptor alpha-wild-type gastrointestinal stromal tumors share KIT activation but not mechanisms of genetic progression with adult gastrointestinal stromal tumors. Cancer Res 67: 9084-9088, 2007.

14. Demetri GD, von Mehren M, Antonescu CR, DeMatteo RP, Ganjoo KN, Maki RG, Pisters PW, Raut CP, Riedel RF, Schuetze S, Sundar HM, Trent JC and Wayne JD: NCCN Task Force report: update on the management of patients with gastrointestinal stromal tumors. J Natl Compr Canc Netw 8 (Suppl 2): S1-S44, 2010.
15. Schaefer M, Hagemann S, Hanna K and Lyko F: Azacytidine inhibits RNA methylation at DNMT2 target sites in human cancer cell lines. Cancer Res 69: 8127-8132, 2009.

16. Ooi SK, Qiu C, Bernstein E, Li K, Jia D, Yang Z, Erdjument-Bromage H, Tempst P, Lin SP, Allis CD, Cheng X and Bestor TH: DNMT3L connects unmethylated lysine 4 of histone H3 to de novo methylation of DNA. Nature 448: 714-717, 2007.

17. Bourc'his D, Xu GL, Lin CS, Bollman B and Bestor TH: Dnmt3L and the establishment of maternal genomic imprints. Science 294: 2536-2539, 2001

18. Jia D, Jurkowska RZ, Zhang X, Jeltsch A and Cheng X: Structure of Dnmt3a bound to Dnmt3L suggests a model for de novo DNA methylation. Nature 449: 248-251, 2007.

19. Zhu D, Hunter SB, Vertino PM and Van Meir EG: Overexpression of MBD2 in glioblastoma maintains epigenetic silencing and inhibits the antiangiogenic function of the tumor suppressor gene BAI1. Cancer Res 71: 5859-5870, 2011.

20. Fuso A, Nicolia V, Cavallaro RA and Scarpa S: DNA methylase and demethylase activities are modulated by one-carbon metabolism in Alzheimer's disease models. J Nutr Biochem 22: 242-251, 2011.

21. Rountree MR, Bachman KE, Herman JG and Baylin SB: DNA methylation, chromatin inheritance, and cancer. Oncogene 20: 3156-3165, 2001.

22. Ding WJ, Fang JY, Chen XY and Peng YS: The expression and clinical significance of DNA methyltransferase proteins in human gastric cancer. Dig Dis Sci 53: 2083-2089, 2008. 